\title{
Study on volatilization characteristic of vanadium and tungsten of vanadium-based selective catalytic reduction
}

\author{
Yue $\mathrm{Liu}^{1,2}$, Hong $\mathrm{Ni}^{3, *}$, Jun $\mathrm{Li}^{1,2}$, and Shuxia $\mathrm{Xie}^{3}$ \\ ${ }^{1}$ China Automotive Technology and Research Center Co., Ltd, China \\ ${ }^{2}$ Tianjin SwARC Automotive Research Laboratory Co., Ltd, China; ${ }^{3}$ Chinese Research Academy of \\ Environmental Sciences, China
}

\begin{abstract}
Keywords: selective catalytic reduction, vanadium pentoxide, tungsten trioxide, volatilization.
\end{abstract}

\begin{abstract}
Vanadium-based selective catalyst reduction (V-SCR) has made significant contributions to De-NOx of diesel vehicles. However, the two main catalyst components, $\mathrm{V}_{2} \mathrm{O}_{5}$ and $\mathrm{WO}_{3}$, are volatile and toxic. Therefore, there are some restrictions for its application on heavy duty diesel vehicles (HDDV) in the CHINA VI stage. In view of this problem, the volatilization rates of two kinds of volatiles under different inlet temperature and test duration were measured on three V-SCR samples from different catalyst manufacturers. The effects of V-SCR inlet temperature and test duration on the volatilization characteristics of the two volatiles on different samples were systematically studied and compared. The emission concentrations of $\mathrm{V}_{2} \mathrm{O}_{5}$ and $\mathrm{WO}_{3}$ at different temperatures were compared with the occupational exposure limits of chemical harmful factors in the workplace which is specified in the GBZ 2.1-2019. The results show that the initial temperature of volatilization of V-SCR is directly related to the technical level of the catalyst itself; whether the volatilization characteristics of VSCR will change with the prolongation of test duration depends on its inlet temperature; $\mathrm{V}_{2} \mathrm{O}_{5}$ emission concentration of $\mathrm{V}$-SCR at $550{ }^{\circ} \mathrm{C}$ can reach a quite high exposure level, and the exposure level of $\mathrm{WO}_{3}$ volatiles at $650{ }^{\circ} \mathrm{C}$ may be equivalent to that of $\mathrm{V}_{2} \mathrm{O}_{5}$ volatiles at $550{ }^{\circ} \mathrm{C}$.
\end{abstract}

\section{Introduction}

Selective catalytic reduction (SCR) has become the most widely used commercial diesel vehicle De-NOx technology, especially in China and Europe [1,2]. The SCR technology used in the IV and V emission stages of heavy-duty diesel vehicles (HDDV) in Europe and China is $\mathrm{V}$-W-Ti based SCR (V-SCR) with $\mathrm{V}_{2} \mathrm{O}_{5}$ as catalyst active substance, $\mathrm{WO}_{3}$ as catalyst assistant and $\mathrm{TiO}_{2}$ as coating material. However, $\mathrm{V}_{2} \mathrm{O}_{5}$ and $\mathrm{WO}_{3}$ are volatile, and the volatilized gas is toxic, among which $\mathrm{V}_{2} \mathrm{O}_{5}$ is identified as suspicious carcinogenic to human by the national occupational health standard GBZ 2.1-2019 [3].

\footnotetext{
* Corresponding author: nihong@vecc.org.cn
} 
In China and Europe, in the IV and V emission stages of HDDV, V-SCR is the unique aftertreatment device with the usual inlet temperature lower than $400{ }^{\circ} \mathrm{C}$ and unlikely to produce volatiles, so the application of V-SCR is relatively safe. From July 1, 2019, China began to implement the CHINA VI emission standard of HDDV [4], in which the particulate matter emission limit was tightened. In order to meet the regulatory requirements, the current prevailing technology is to install a diesel particle filter (DPF) in front of SCR, and then burn and remove the accumulated PM through active or passive regeneration. If the DPF adopts the active regeneration mode, the exhaust temperature may rise to $750{ }^{\circ} \mathrm{C}$ instantaneously, while exceeding the melting point of $\mathrm{V}_{2} \mathrm{O}_{5}$ and causing volatilization. Therefore, the new standard [4] puts forward special requirements for V-SCR that the inlet temperature lower than $550{ }^{\circ} \mathrm{C}$. If V-SCR technology is applied, the upstream DPF must adopt mild passive regeneration mode and verify the volatilization characteristics of vanadium volatiles. As for $\mathrm{WO}_{3}$, although its toxicity level is relatively low, some researchers also showed interests and studied it with $\mathrm{V}_{2} \mathrm{O}_{5}$ synchronous as well, and found that its volatilization rate was higher than $\mathrm{V}_{2} \mathrm{O}_{5}[2,5-7]$.

With regard to the influencing factors of volatilization characteristics of V-SCR, Yannopoulos et al. [8] found that the main way of volatilization of $\mathrm{V}_{2} \mathrm{O}_{5}$ and $\mathrm{WO}_{3}$ is not by heat, but by the formation of volatile hydroxyl compounds with water in the exhaust gas. The existence of water can promote the volatilization and decrease the volatilization temperature. Liu et al. [7] showed that the technical level and aging degree of the catalyst itself can also lead to different volatilization characteristics. However, at present, there are only a little of data from foreign laboratories, which mainly focused on the high-temperature effect, and the test conditions such as water vapor content and the evaluation device are different. Thus, it is not convenient for data comparison. On the other hand, with the upgrading of emission regulations, the technical level of V-SCR has being improved, and the samples studied in these public papers cannot represent the technical level of V-SCR newly in China, so it is worthy to study the $\mathrm{V}_{2} \mathrm{O}_{5}$ and $\mathrm{WO}_{3}$ volatilization characteristics of state of the art V-SCR products used in domestic market. In view of this, three V-SCR samples (the technical level differences between them are unknow) from different catalyst manufacturers were tested in a simulated operating environment with a fixed water vapor concentration of $10 \mathrm{vol} . \%$ (about the maximum concentration of water vapor in the exhaust of diesel vehicles), and the volatilization rate of $\mathrm{V}_{2} \mathrm{O}_{5}$ and $\mathrm{WO}_{3}$ at different inlet temperatures with different test duration were tested. The effects of V-SCR inlet temperature and test duration on the volatilization characteristics of the two volatiles on different samples were systematically studied and compared. The emission concentrations of $\mathrm{V}_{2} \mathrm{O}_{5}$ and $\mathrm{WO}_{3}$ at different temperatures were compared with the occupational exposure limits of chemical harmful factors in the workplace which is specified in the GBZ 2.1-2019 [3].

\section{Experimental}

\subsection{The capture of Volatiles}

The three V-SCR samples were named as sample A, B and C separately. Take 6 small samples from each V-SCR sample for testing at different temperature points separately, the size of small sample was about $\Phi 20 \mathrm{~mm} \times 25 \mathrm{~mm}$. Each small sample was put in the constant temperature zone of the quartz tube of the reactor. Two quartz capture traps contained a specific amount of $\gamma-\mathrm{Al}_{2} \mathrm{O}_{3}(7.0 \mathrm{~g}$, particle diameter $2-4 \mathrm{~mm})$ as the adsorbent of volatiles were put in the constant temperature zone and the low temperature zone of the quartz tube separately. Use thermocouple to measure the inlet temperature of the sample, and the 
measuring point was at the center line and $1 \mathrm{~cm}$ before the front end of the sample. The Schematic of volatiles capture test is shown in Figure 1.

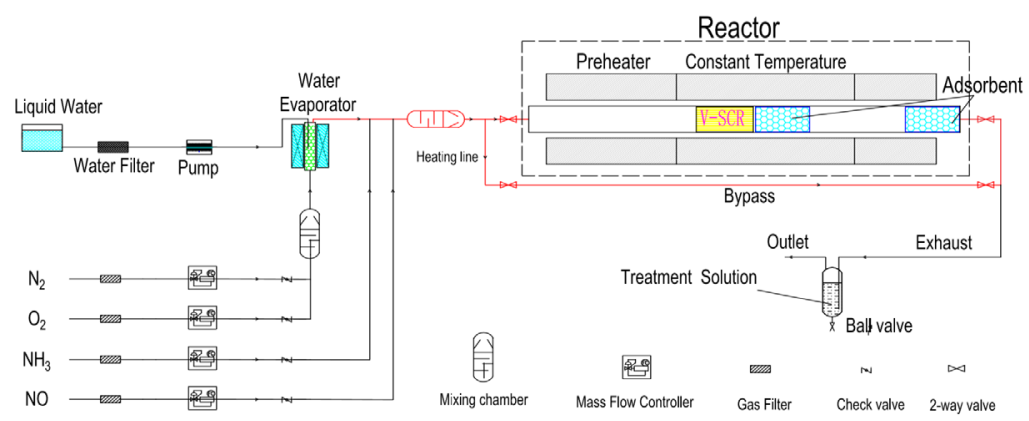

Fig. 1. Schematic of volatiles capture test.

During all the experiments, a space velocity (SV) of $35000 \mathrm{~h}^{-1}$ was used. To minimize the volatilization in the process of transient temperature ramps, 5 vol. $\% \mathrm{O}_{2}$ and balance $\mathrm{N}_{2}$ were introduced into the quartz tube, and the furnace temperature was programmed heating until the inlet temperature of small sample reached the desired temperature within $1 \mathrm{~h}$. When the inlet temperature reached the desired point, 10 vol.\% water vapor, $250 \mathrm{ppm} \mathrm{NO}$ and 250 ppm $\mathrm{NH}_{3}$ were added immediately, meanwhile the test duration begun to calculate. It was not until reaching the target duration that the heating was stopped and the water supply with all the gases except $\mathrm{N}_{2}$ was cut down. $\mathrm{N}_{2}$ was used to cool the reactor rapidly to below $100{ }^{\circ} \mathrm{C}$. Then take the two quartz capture traps out to analyze, and replace the fresh adsorbent to proceed the next testing stage.

\subsection{Analysis method of adsorbent}

Take out the adsorbent and then grind them into powder (particle size $\leq 0.15 \mathrm{~mm}$ ) separately. Three test portions of $0.2 \mathrm{~g}$ for each test sample were transferred respectively to the Teflon pressure vessels with a mixture of $12 \mathrm{ml}$ of $\mathrm{HCl}, 2 \mathrm{ml}$ of $\mathrm{HNO}_{3}, 0.5 \mathrm{ml}$ of $\mathrm{HF}$. The samples were heated in a microwave digestion instrument at $200{ }^{\circ} \mathrm{C}$ for $25 \mathrm{~min}$. After cooling, the test solutions were diluted to $50 \mathrm{~mL}$ with high purity water. The concentrations of $\mathrm{V}, \mathrm{W}$ and Ti were determined by Inductively Coupled Plasma - Optical Emission Spectroscopy (ICPOES) from Perkin Elmer. Ti served as an internal marker for catalyst dust spill over. It is required that the relative standard deviation of each element in three parallel test portions should not exceed $5 \%$.

\subsection{Calculation of minimum quantitative detection limit}

According to HJ 168-2010 [9], the method detection limit (MDL) of 4 times was used as the minimum quantitative detection limit. The MDL calculation method is according to the method of "the target substance is detected in the blank test", fresh $\gamma-\mathrm{Al}_{2} \mathrm{O}_{3}$ from the same batch as the tests was taken as the blank sample and was determined 10 times in parallel according to all the steps for adsorbent analysis. MDL was calculated using Equation 1.

$$
\mathrm{MDL}=\mathrm{t}_{(\mathrm{n}-1,0.99)} \cdot \mathrm{S}
$$

MDL is the method detection limit, $\mu \mathrm{g} / \mathrm{g} ; \mathbf{t}$ (n-1, 0.99) is the $\mathrm{t}$ distribution (one side) when the freedom degree is $10-1$ and the confidence is $99 \%$, and the reference value is 2.821 ; $\boldsymbol{S}$ is the standard deviation of parallel determination results for 10 times, $\mu \mathrm{g} / \mathrm{g}$. 


\subsection{Results calculation}

\subsubsection{Volatilization rate}

$\mathrm{V}_{2} \mathrm{O}_{5}$ and $\mathrm{WO}_{3}$ volatilization rates were calculated respectively using Equations 2 and 3.

$$
\begin{aligned}
& Q_{V 205}=\left(\frac{182}{102} C_{V}-\frac{48}{80} P_{V: T i} \cdot C_{T i}\right) \frac{m}{V \cdot t} \\
& Q_{W 03}=\left(\frac{232}{184} C_{W}-\frac{48}{80} P_{W: T i} \cdot C_{T i}\right) \frac{m}{V \cdot t}
\end{aligned}
$$

$\boldsymbol{Q}_{\boldsymbol{V} 2 \boldsymbol{O} \text { 5 }}$ and $\boldsymbol{Q}_{\boldsymbol{W} \text { O3 }}$ are the $\mathrm{V}_{2} \mathrm{O}_{5}$ and $\mathrm{WO}_{3}$ volatilization rate respectively, $\mu \mathrm{g} /(\mathrm{L} \cdot \mathrm{h}), \boldsymbol{C}_{\boldsymbol{V}}, \boldsymbol{C}_{\boldsymbol{W}}$ and $\boldsymbol{C}_{\boldsymbol{T}}$ are the concentration of V, W and Ti found in the absorbent respectively, $\mu \mathrm{g} / \mathrm{g}, \boldsymbol{m}$ is the mass of absorbent in the hot trap, $\boldsymbol{P}_{V: T i}$ and $\boldsymbol{P}_{\boldsymbol{W}: T i}$ are the loading ratio of $\mathrm{V}_{2} \mathrm{O}_{5}$ and $\mathrm{WO}_{3}$ for each V-SCR sample, $\boldsymbol{V}$ is the volume of V-SCR small sample, $\boldsymbol{t}$ is the duration hours at the specified temperature.

If $\mathrm{V}, \mathrm{W}$ and Ti elements are detected in the adsorbent of cold trap, the results should be calculated in the same way and included in the volatilization rate. The volatilization rate of $\mathrm{V}_{2} \mathrm{O}_{5}$ and $\mathrm{WO}_{3}$ obtained from cold trap adsorbent should not exceed $5 \%$ of that of corresponding hot trap adsorbent respectively.

\subsubsection{Emission concentration}

$\mathrm{V}_{2} \mathrm{O}_{5}$ and $\mathrm{WO}_{3}$ emission concentrations was calculated using Equation 4.

$$
R_{i}=\frac{1000 \cdot Q_{i}}{\mathrm{SV}}
$$

$\boldsymbol{R}_{\boldsymbol{i}}$ is the emission concentration of $\mathrm{V}_{2} \mathrm{O}_{5}$ or $\mathrm{WO}_{3}, \mu \mathrm{g} / \mathrm{m}^{3}$, i represents $\mathrm{V}_{2} \mathrm{O}_{5}$ or $\mathrm{WO}_{3} ; \boldsymbol{Q}_{\boldsymbol{i}}$ is volatilization rate of $\mathrm{V}_{2} \mathrm{O}_{5}$ or $\mathrm{WO}, \mu \mathrm{g} /(\mathrm{L} \cdot \mathrm{h})$, i represents $\mathrm{V}_{2} \mathrm{O}_{5}$ or $\mathrm{WO}_{3}$; $\mathbf{S V}$ is the space velocity fixed at $35000 \mathrm{~h}^{-1}$.

\section{Results and discussion}

\subsection{Effect of inlet temperature on volatilization}

The inlet temperature of V-SCR for CHINA VI should be lower than $550{ }^{\circ} \mathrm{C}$ [4]. In order to verify the influence of inlet temperature on volatilization rate, the volatilization rates of the two volatiles of three samples were tested at six inlet temperature points between $400{ }^{\circ} \mathrm{C}$ and $700{ }^{\circ} \mathrm{C}$ for $18 \mathrm{~h}$. The comparison results are shown in Figure 2.
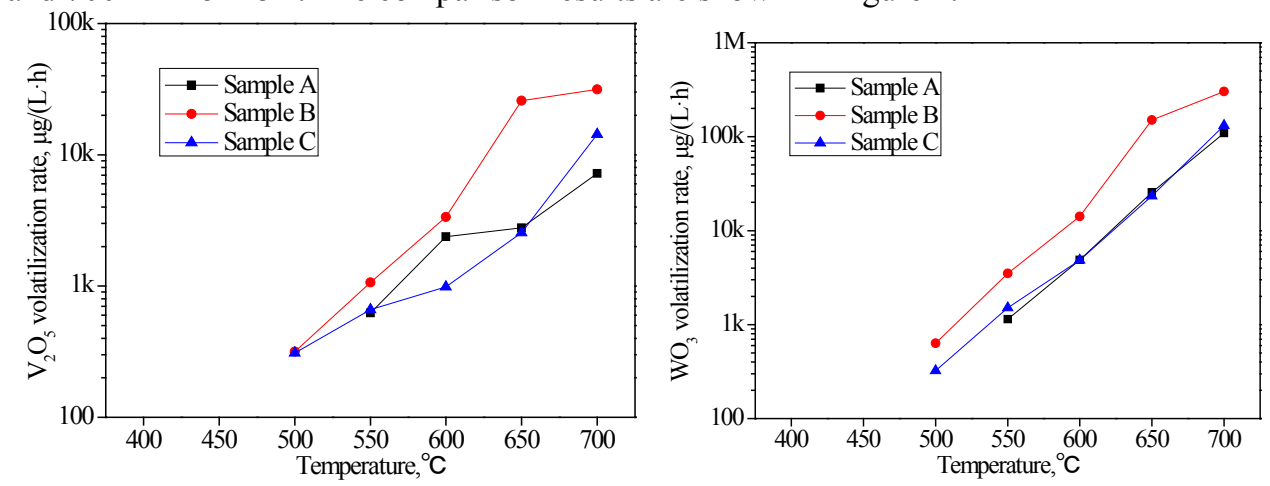

Fig. 2. Volatilization rate of $\mathrm{V}_{2} \mathrm{O}_{5}$ and $\mathrm{WO}_{3}$ within $18 \mathrm{~h}$ as a function of inlet temperature. 
It can be seen from Figure 2 that the initial temperature of volatilization for the three samples were slightly different. Thereinto, a small amount of volatilization of $\mathrm{V}_{2} \mathrm{O}_{5}$ and $\mathrm{WO}_{3}$ occurred early at $500{ }^{\circ} \mathrm{C}$ for sample $\mathrm{B}$ and $\mathrm{C}$, and then at $550{ }^{\circ} \mathrm{C}$ for sample A. For the same sample, the initial temperatures of volatilization of $\mathrm{V}_{2} \mathrm{O}_{5}$ and $\mathrm{WO}_{3}$ were the same. As for the trend of the curve, it can be seen that the $\mathrm{V}_{2} \mathrm{O}_{5}$ and $\mathrm{WO}_{3}$ volatilization rates of the three samples turned out an approximate exponential growth with the rise of temperature, which is different from the stable linear growth trend that observed by Liu et al. [7] in the temperature range of $500{ }^{\circ} \mathrm{C} \sim 700{ }^{\circ} \mathrm{C}$ on reactor with 10.5 vol.\% water vapor during $22 \mathrm{~h}$. Compared with the volatilization rate difference between samples, it can be found that the volatilization rates of the two volatiles on sample B were higher than those of samples A and $\mathrm{C}$ at all the testing temperature points, indicating that sample $\mathrm{B}$ had stronger volatility. In addition, The HDDV emission standard of CHINA VI requires that there should be no leakage of vanadium containing compounds in the whole life cycle of HDDV installed with $\mathrm{V}$-SCR. The test requirement is that the volatilization of vanadium in the adsorbent should be lower than the minimum quantitative detection limit when the inlet temperature of V-SCR is kept at $550{ }^{\circ} \mathrm{C}$ for $18 \mathrm{~h}$, and the matching ammonia slip catalyst is permitted to be at the back end of V-SCR as a whole sample. However, it is observed that all three samples at $550{ }^{\circ} \mathrm{C}$ produced the vanadium volatiles. Therefore, it can be seen that in order to meet the requirements of the regulations, it is necessary to further improve the technical level of the products so as to inhibit volatilization, or simultaneously use the capture measures of volatiles to prevent their leakage. For example, Hoej et al. [2] found that ammonia slip catalyst had an excellent adsorption effect on volatiles.

\subsection{Effect of test duration on volatilization}

At the constant inlet temperature, prolonging the duration can accumulate the heat effect and aggravate the catalyst aging degree of $\mathrm{V}$-SCR, which may promote the volatilization of volatiles. T/CAEPI 12.2-2017 [10], a standard on technical requirements for environmental protection products, puts forward that the durability test requirement of V-SCR is aging at $550{ }^{\circ} \mathrm{C}$ for $200 \mathrm{~h}$. In order to verify the variation of volatilization rate of the two volatiles during the duration, the two volatiles volatilization rates of three samples at $550{ }^{\circ} \mathrm{C}$ in $0-18$ h, 19-50 h, 51-100 h and 101-200 h (18 h, $50 \mathrm{~h}, 100 \mathrm{~h}, 200 \mathrm{~h}$ for short), four separate stages, were tested respectively. The results are shown in Figure 3.
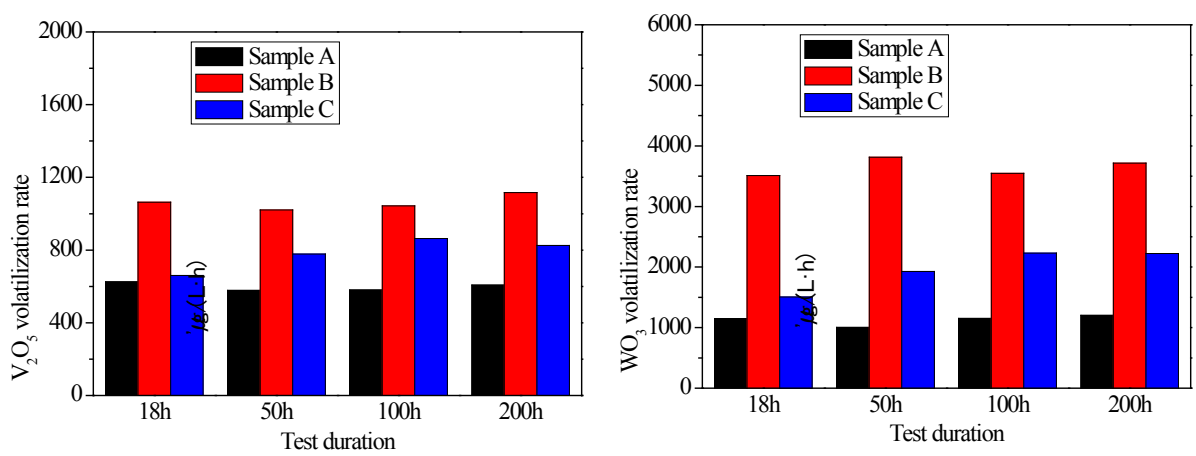

Fig. 3. Volatilization rate of $\mathrm{V}_{2} \mathrm{O}_{5}$ and $\mathrm{WO}_{3}$ at $550{ }^{\circ} \mathrm{C}$ in different test duration stages.

It can be seen from Figure 3 that the volatilization rates of $\mathrm{V}_{2} \mathrm{O}_{5}$ and $\mathrm{WO}_{3}$ of the three samples at $550{ }^{\circ} \mathrm{C}$ had no obvious variation in the four test duration stages, which was consistent with the phenomenon observed by Hoej et al. [2] from the volatilization 
performance of a V-SCR sample within $200 \mathrm{~h}$ at the same temperature. The results show that the samples still kept good stability even if the test duration was extended to $200 \mathrm{~h}$ at $550{ }^{\circ} \mathrm{C}$, and the heat accumulated during the test had no obvious influence on the volatilization rate of volatiles.

In order to compare the effect of test duration on the volatilization rate at higher temperature, the volatilization rates of the two volatiles in $18 \mathrm{~h}$ and $50 \mathrm{~h}$ at $600{ }^{\circ} \mathrm{C}$ were tested. The results are shown in Figure 4.
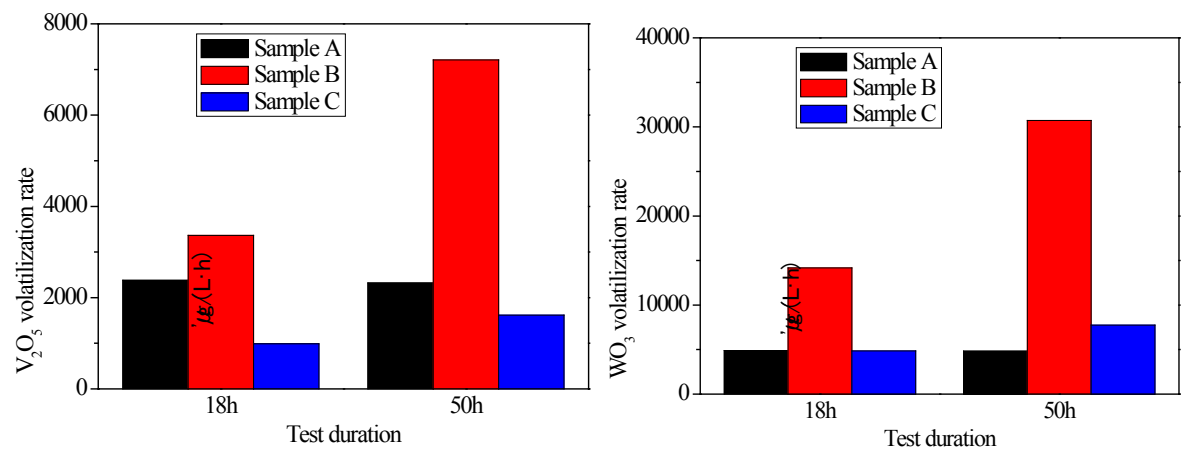

Fig. 4. Volatilization rate of $\mathrm{V}_{2} \mathrm{O}_{5}$ and $\mathrm{WO}_{3}$ at $600{ }^{\circ} \mathrm{C}$ in two test duration stages.

The phenomena in Figure 4 are slightly different from that in Figure 3 . At $600{ }^{\circ} \mathrm{C}$, only the volatilization rates of two volatiles of sample A had no significant variation in the two duration stages, while the volatilization rates of $\mathrm{V}_{2} \mathrm{O}_{5}$ and $\mathrm{WO}_{3}$ of sample $\mathrm{B}$ and sample $\mathrm{C}$ in the second stage were significantly raised compared with those in the first stage, with the corresponding increases of $114 \%$ and $117 \%$ for sample B and $64 \%$ and $60 \%$ for sample C respectively. It can be inferred that the order of hydrothermal stability of the three samples from high to low was $\mathrm{A}>\mathrm{C}>\mathrm{B}$ at $600{ }^{\circ} \mathrm{C}$. At this temperature, sample $\mathrm{B}$ and sample $\mathrm{C}$ showed obvious deterioration, which promoted the volatilization of $\mathrm{V}_{2} \mathrm{O}_{5}$ and $\mathrm{WO}_{3}$. Furthermore, it is observed that the volatilization rates of $\mathrm{V}_{2} \mathrm{O}_{5}$ and $\mathrm{WO}_{3}$ of sample $\mathrm{B}$ and sample $\mathrm{C}$ were basically the same in different duration stages, and the volatilization rate ratio of the two volatiles did not change significantly, indicating that prolonging the test duration or aggravating the aging degree of the catalyst had no significant effect on the volatilization rate ratio of the two volatiles.

\subsection{Comparison of volatilization characteristics between $\mathrm{V}_{2} \mathrm{O}_{5}$ and $\mathrm{WO}_{3}$}

Generally, $\mathrm{V}_{2} \mathrm{O}_{5}$ loading is 1 wt.\% 3 wt.\% in $\mathrm{V}$-SCR catalyst coating, while $\mathrm{WO}_{3}$ loading range is wider, which can be $1 \mathrm{wt} . \% \sim 15 \mathrm{wt} . \%$, however, its loading is higher than $\mathrm{V}_{2} \mathrm{O}_{5}$ for the most part. The loading ratios of $\mathrm{WO}_{3}$ to $\mathrm{V}_{2} \mathrm{O}_{5}$ corresponding to the three samples is in the order of $\mathrm{A}>\mathrm{B}>\mathrm{C}$. In order to compare the real volatilization characteristics of the two volatiles and exclude the influence of loading's difference on volatilization rate, the volatilization rate ratio of $\mathrm{WO}_{3}$ and $\mathrm{V}_{2} \mathrm{O}_{5}$ corresponding to the same loading was calculated according to Equation 5, and the results were shown in Figure 5.

$$
Y=\frac{Q_{W O 3}}{P_{W: V} Q_{V 205}}
$$

$\boldsymbol{Y}$ is the volatilization rate ratio of $\mathrm{WO}_{3}$ to $\mathrm{V}_{2} \mathrm{O}_{5}$ corresponding to the equal loading; $P_{W: V}$ is the load mass ratio of $\mathrm{WO}_{3}$ to $\mathrm{V}_{2} \mathrm{O}_{5}$ on V-SCR. 


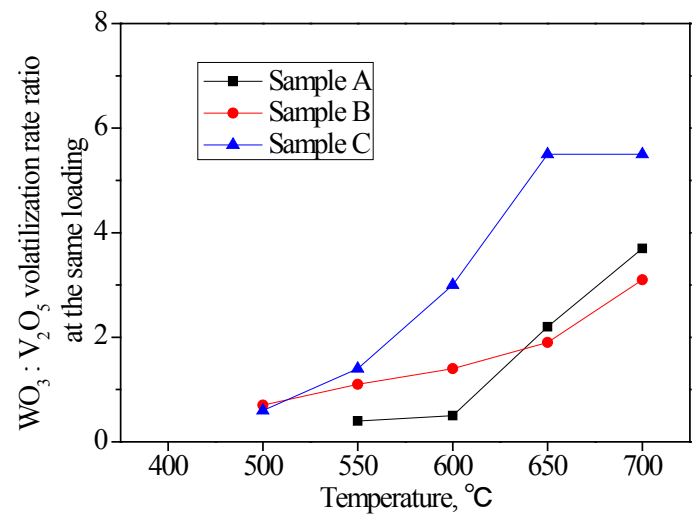

Fig. 5. Volatilization rate ratio of $\mathrm{WO}_{3}$ to $\mathrm{V}_{2} \mathrm{O}_{5}$ corresponding to the equal loading as a function of temperature.

It can be seen from Figure 5 that the volatilization rate ratio of $\mathrm{WO}_{3}$ to $\mathrm{V}_{2} \mathrm{O}_{5}$ corresponding to the equal loading of the three samples ranged from 0.4 to 5.5 , and increased with the rise of temperature. The volatilization rate ratio of $\mathrm{WO}_{3}$ to $\mathrm{V}_{2} \mathrm{O}_{5}$ corresponding to the equal loading was less than 1.0 for sample A at $550{ }^{\circ} \mathrm{C}$ and $600{ }^{\circ} \mathrm{C}$, and samples $\mathrm{B}$ and $\mathrm{C}$ at $500{ }^{\circ} \mathrm{C}$ separately, which indicates that the actual volatility of $\mathrm{WO}_{3}$ was slightly weaker than that of $\mathrm{V}_{2} \mathrm{O}_{5}$ under the specific condition. With the increase of temperature, the volatilization rate ratio of $\mathrm{WO}_{3}$ to $\mathrm{V}_{2} \mathrm{O}_{5}$ raised, which indicates that the increase of temperature has a greater promotion effect on the volatility of $\mathrm{WO}_{3}$ than that of $\mathrm{V}_{2} \mathrm{O}_{5}$.

\subsection{Comparison of volatiles' concentrations in exhaust with their occupational exposure limits (OELs) in workplace}

In order to evaluate the harmful effects degree of $\mathrm{V}_{2} \mathrm{O}_{5}$ and $\mathrm{WO}_{3}$ volatiles from $\mathrm{V}$-SCR if discharge them directly into the respiratory zone of human without being adsorbed, the OELs and exposure levels for chemical hazardous factors in the workplace, which were constituted on the basis of the research results of toxicology and epidemiology and regulated in the mandatory occupational health standard GBZ 2.1-2019 [3] issued by the National Health Commission of China was referred to. And the $\mathrm{V}_{2} \mathrm{O}_{5}$ and $\mathrm{WO}_{3}$ emission concentrations of $\mathrm{V}$ SCR (assuming that the space is full of diesel exhaust) can be compared with the OELs of $\mathrm{V}_{2} \mathrm{O}_{5}$ and $\mathrm{WO}_{3}$ to evaluate the exposure level. GBZ 2.1-2019 [3] divides the exposure level into five grades (Table 1).

Table 1. Description of occupational exposure levels

\begin{tabular}{ll}
\hline Grade & Description \\
\hline $0(\leqslant 1 \%)$ & $\begin{array}{l}\text { No exposure, no action required } \\
\text { Very low exposure, no correlation effect according to the available } \\
\text { information }\end{array}$ \\
II $(>1 \%, \leq 10 \%)$ & Medium exposure, but no obvious health effect \\
III $(>50 \%$, & Significant exposure, requires action to limit the exposure activity \\
$\leq 100 \%)$ & Exceed OELs \\
IV $(>100 \%)$ &
\end{tabular}

One type of OELs is the permissible concentration-time weighted average (PC-TWA), which means the allowable average exposure concentration for $8 \mathrm{~h}$ working day and $40 \mathrm{~h}$ working week. GBZ 2.1-2019 [3] specifies the PC-TWA of $\mathrm{V}_{2} \mathrm{O}_{5}$ is $50 \mu \mathrm{g} / \mathrm{m}^{3}$, and its critical 
adverse health effect is respiratory system damage; the PC-TWA of W and its insoluble compounds ( $\mathrm{WO}_{3}$ belongs to this category) is $5000 \mu \mathrm{g} / \mathrm{m}^{3}$ according to $\mathrm{W}$ and equivalent to $6304 \mu \mathrm{g} / \mathrm{m}^{3}$ of $\mathrm{WO}_{3}$, and its critical adverse health effect is lower respiratory tract stimulation. The comparison results of ratio of $\mathrm{V}_{2} \mathrm{O}_{5}$ and $\mathrm{WO}_{3}$ emission concentrations of the three $\mathrm{V}$ SCR samples within $18 \mathrm{~h}$ at $500{ }^{\circ} \mathrm{C}-700{ }^{\circ} \mathrm{C}$ with the corresponding PC-TWA in the workplace (named as exposure ratio) are shown in Figure 6.
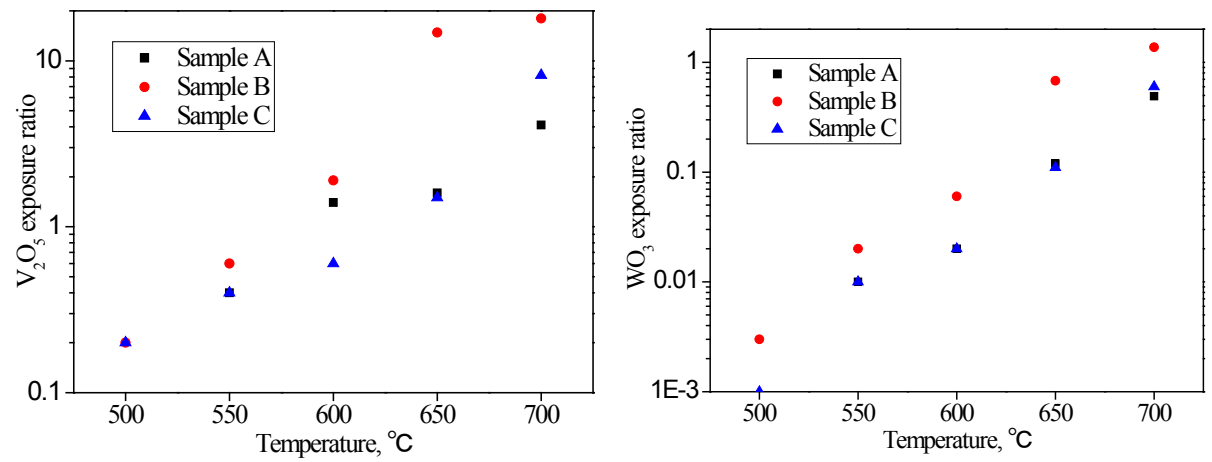

Fig. 6. The ratio of $\mathrm{V}_{2} \mathrm{O}_{5}$ and $\mathrm{WO}_{3}$ emission concentration to corresponding PC-TWA at $500{ }^{\circ} \mathrm{C}-$ $700{ }^{\circ} \mathrm{C}$.

As shown in Figure 6, at the same temperature, the exposure ratio of $\mathrm{V}_{2} \mathrm{O}_{5}$ was about two orders of magnitude higher than that of $\mathrm{WO}_{3}$. According to the description of exposure level in Table 1, it can be seen that, for $\mathrm{V}_{2} \mathrm{O}_{5}$ at $500{ }^{\circ} \mathrm{C}$, the exposure level of volatiles reached level II, the level with contact but no obvious health effect; at $550{ }^{\circ} \mathrm{C}$, sample B reached level III of significant exposure; at $600{ }^{\circ} \mathrm{C}$, except for sample $\mathrm{C}$ which still kept the exposure level of grade III, all others exceeded PC-TWA and reached level IV. Compared with $\mathrm{V}_{2} \mathrm{O}_{5}$, the exposure level of $\mathrm{WO}_{3}$ is relatively low. At the temperature below $650{ }^{\circ} \mathrm{C}$, the exposure level of $\mathrm{WO}_{3}$ volatiles was about two orders of magnitude lower than that of $\mathrm{V}_{2} \mathrm{O}_{5}$. It's noteworthy that at $650{ }^{\circ} \mathrm{C}$, the $\mathrm{WO}_{3}$ exposure level of samples $\mathrm{A}$ and $\mathrm{C}$ reached level II while sample $\mathrm{B}$ even reached level III, and the exposure level of $\mathrm{WO}_{3}$ of three samples was equivalent to that of $\mathrm{V}_{2} \mathrm{O}_{5}$ at $550{ }^{\circ} \mathrm{C}$ actually.

\section{Summary and conclusions}

Based on the test data of the samples investigated in this paper, the following conclusions can be drawn:

(1) The initial volatilization temperature of V-SCR is directly related to the technical level of the catalyst itself. $\mathrm{V}_{2} \mathrm{O}_{5}$ and $\mathrm{WO}_{3}$ begin to volatilize at the same temperature on one $\mathrm{V}$ SCR.

(2) The $\mathrm{V}_{2} \mathrm{O}_{5}$ and $\mathrm{WO}_{3}$ volatilization rates both have an approximate exponential growth with the rise of inlet temperature of V-SCR.

(3) Whether the volatilization characteristics of V-SCR will change with the prolongation of test duration depends on its inlet temperature. When the temperature is below $550{ }^{\circ} \mathrm{C}$, the extension of test duration has no obvious effect on the volatilization characteristics of V-SCR. However, when the temperature is over $550{ }^{\circ} \mathrm{C}$, the extension of test duration will lead to the simultaneous increase of $\mathrm{V}_{2} \mathrm{O}_{5}$ and $\mathrm{WO}_{3}$ volatilization of $\mathrm{V}-\mathrm{SCR}$ with poor hydrothermal stability.

(4) The results of comparison of the volatility of $\mathrm{V}_{2} \mathrm{O}_{5}$ and $\mathrm{WO}_{3}$ are related to the inlet temperature of V-SCR. At the temperature near the initial volatilization temperature, the 
volatility of $\mathrm{WO}_{3}$ is generally weaker than that of $\mathrm{V}_{2} \mathrm{O}_{5}$, however, it can rapidly exceed the $\mathrm{V}_{2} \mathrm{O}_{5}$ volatility with the rise of temperature.

(5) Keeping the inlet temperature of V-SCR below $550{ }^{\circ} \mathrm{C}$ is the key to its safe use. As a hypothesis, make the space full of diesel exhaust, the $\mathrm{V}_{2} \mathrm{O}_{5}$ emission concentration of $\mathrm{V}$ SCR at $550{ }^{\circ} \mathrm{C}$ can reach the exposure level of II or even III of chemical hazards in the workplace. For $\mathrm{WO}_{3}$, due to its low toxicity, when the temperature does not exceed $550{ }^{\circ} \mathrm{C}$, the emission concentration of volatiles is at a low exposure level. However, with the increase of temperature, the volatilization rate of $\mathrm{WO}_{3}$ greatly increases, and the emission concentration of $\mathrm{WO}_{3}$ can reach a quite high exposure level.

\section{References}

1. Alemany L. J., Berti F., Busca G., et al. Characterization and Composition of Commercial $\mathrm{V}_{2} \mathrm{O}_{5}-\mathrm{WO}_{3}-\mathrm{TiO}_{2} \mathrm{SCR}$ Catalysts [J]. Applied Catalysis B: Environmental, 1996, 10(2): 299-311.

2. Hoej J., Beier M. J.. Vanadium-Based SCR Systems: Release of Vanadium and Tungsten during Operation and Possibilities for Reducing Vanadium Emissions [J]. SAE Technical Paper, 2014-01-1626.

3. National Health Commission of P.R.C. GBZ2.1-2019 Occupational exposure limits for hazardous agents in the workplace-Part 1: Chemical hazardous agents [S]. Standards Press of China, 2019.

4. Ministry of Ecology and Environment of P.R.C., State Administration for Market Regulation. GB 17691-2018 Limits and measurement methods for emissions from diesel fuelled heavy-duty vehicles (CHINA VI) [S]. China Environmental Science Press, 2018.

5. Chapman D. M.. Behavior of titania-supported vanadia and tungsta SCR catalysts at high temperatures in reactant streams: Tungsten and vanadium oxide and hydroxide vapor pressure reduction by surficial stabilization [J]. Applied Catalysis A: General, 2011, 392: 143-150.

6. Liu Z. G., Ottinger N. A., Cremeens C. M.. Methods for Quantifying the Release of Vanadium from Engine Exhaust Aftertreatment Catalysts [J]. SAE Technical Paper, 2012-01-0887.

7. Liu Z. G., Ottinger N. A., Cremeens C. M.. Vanadium and tungsten release from Vbased selective catalytic reduction diesel aftertreatment [J]. Atmospheric Environmental, 2015, 104: 154-161.

8. Yannopoulos, L. N.. Thermodynamics of the vanadium pentoxide (solid or liquid)-water vapor system [J]. Journal of Physical Chemistry, 1968, 72(9):3293-3296.

9. Ministry of Environmental Protection. HJ 168-2010 Environmental monitoring Technical guideline on drawing and revising analytic method standards $[\mathrm{S}]$. China Environmental Science Press, 2010.

10. China Association of Environmental Protection Industry. T/CAEPI 12.2-2017 Technical requirements for diesel vehicle exhaust after-treatment devices Part 2: Selective catalytic reduction (SCR) [S]. China Environmental Science Press, 2017. 